\title{
Densification and Microstructural Evolutions during Reaction Sintering of SiC-Si-C Powder Compacts
}

\author{
H. Asgharzadeh ${ }^{1}$ and N. Ehsani ${ }^{2}$ \\ ${ }^{1}$ Department of Materials Engineering, Faculty of Mechanical Engineering, University of Tabriz, P.O. Box 51666, Tabriz 16471, Iran \\ ${ }^{2}$ Faculty of Materials and Manufacturing Technology, Malek Ashtar University of Technology, Tehran, Iran
}

Correspondence should be addressed to H. Asgharzadeh, asgharzadeh.hamed@gmail.com

Received 11 May 2011; Accepted 6 June 2011

Academic Editors: J. F. Bartolomé, U. Gomes, and W. Jiang

Copyright (C) $2011 \mathrm{H}$. Asgharzadeh and N. Ehsani. This is an open access article distributed under the Creative Commons Attribution License, which permits unrestricted use, distribution, and reproduction in any medium, provided the original work is properly cited.

\begin{abstract}
Porous SiC-Si-C ceramics were produced by reaction sintering (RS) of silicon carbide, silicon, and carbon powder compacts in the temperature range of $1400-1600^{\circ} \mathrm{C}$. The effects of chemical composition of the starting powder, initial SiC particle size, and reaction sintering temperature and duration on the densification and microstructure of ceramic materials were studied. The results showed that increasing the amount of $\mathrm{Si}$ and/or $\mathrm{C}$ powders in the starting powder mixture had a detrimental influence on the densification of ceramic material as a result of higher amount of remained silicon and carbon phases in the ceramic specimen. Increasing the RS temperature also degraded densification due to the melting of Si and coming out of it from compact during heating. Nevertheless, densification was improved by increasing the RS duration. Using nanometric SiC particles in the starting powder mixture improved the densification compared to that of micrometric ones especially at longer RS processing duration.
\end{abstract}

\section{Introduction}

Silicon carbide $(\mathrm{SiC})$ was conventionally used in various industries as abrasive and cutting tools, structural materials, automobile parts, electric systems, electronic circuit elements, and heating elements. Nowadays, $\mathrm{SiC}$ is also attractive material for semiconductor production equipment parts, optical mirror devices in space, and fusion reactor structural applications [1]. The wide applications of $\mathrm{SiC}$ are attributed to the combination of low density, high stiffness, high hardness, high fracture toughness, high thermal and chemical stability, and good thermal and oxidation resistance $[1,2]$.

$\mathrm{SiC}$ parts have been principally produced by sintering method. However, the conventional sintering of $\mathrm{SiC}$ powders is considerably inhibited due to the strong covalent bonds that impose low values of self-diffusion of carbon and silicon within $\mathrm{SiC}$ structure $[3,4]$. Therefore, $\mathrm{SiC}$ powders should be sintered at very high temperatures $\left(>2000^{\circ} \mathrm{C}\right)$ for bulk fabrication of high-density ceramics. Using additives and/or applying pressure during sintering (hot pressing) can be employed to lower the sintering temperature. Gubernat et al. [4] have shown that SiC powders can be densified at temperatures between 1850 and $2000^{\circ} \mathrm{C}$ with the addition of some oxides, for example, $\mathrm{Al}_{2} \mathrm{O}_{3}, \mathrm{Y}_{2} \mathrm{O}_{3}$, and $\mathrm{MgO}$. Yano et al. [5] have produced $\mathrm{SiC}$ ceramics with high densities (95-99\% theoretical) by hot pressing method at temperature range of $1700-1800^{\circ} \mathrm{C}$, pressure of $30 \mathrm{MPa}$, and the use of aluminum, boron, and carbon dopant materials. Another promising method for production of $\mathrm{SiC}$ parts at lower temperatures is reaction sintering (RS) process. Employing RS can lower the processing temperatures to $1425-1500^{\circ} \mathrm{C}$ [2]. This has been attributed to the exothermic heat released during the reaction sintering between silicon and carbon to form SiC. Production of dense structure, good shape capability, low cost, and high purity are the other advantages of RS method [1]. The RS process is typically involving the infiltration of liquid silicon into a porous preform containing silicon carbide, and carbon has been extensively studied in the past [6-10]. An in situ reaction occurs between silicon and carbon to produce a secondary SiC phase, which then bonds the original $\mathrm{SiC}$ particles [3]. Residual pores and space not occupied by silicon carbide are filled with liquid silicon. It is well known $[11,12]$ that one limiting factor to obtain $\mathrm{SiC}$ parts with high strength is the amount of free silicon in the composites since the brittle free silicon phase and interfaces between $\mathrm{SiC}$ and $\mathrm{Si}$ are preferential paths for fracture. 
Additionally, the mechanical properties, for example, strength, modulus of elasticity, and fracture toughness deteriorate due to increasing the amount of residual silicon phase especially at high temperatures [13-15]. Some studies [12, 16] have been performed in order to reduce the free silicon content in SiC-Si ceramics and enhance the mechanical properties. For instance, Blecha et al. [16] have suggested using $\mathrm{SiC}$ powders with different particle sizes.

The process chosen in this paper is a modification on reaction sintering process to reduce the free silicon content. The major difference between this approach and the typical reaction sintering process is that liquid silicon is not infiltrated into the porous $\mathrm{SiC}-\mathrm{C}$ compact. Instead, the $\mathrm{SiC}$ parts are made by heating of compacts including $\mathrm{SiC}, \mathrm{Si}$, and $\mathrm{C}$ powder mixtures to promote reaction sintering. Therefore, the aim of the present study is to investigate the possibility of producing $\mathrm{SiC}$ ceramics through the $\mathrm{RS}$ of $\mathrm{SiC}, \mathrm{Si}$, and $\mathrm{C}$ powders. The reaction sintering temperature and time were optimized to get ceramics with minimum residual Si and $\mathrm{C}$. The role of the chemical composition of the initial powder and the size of $\mathrm{SiC}$ particles on the microstructure and densification of ceramic parts are addressed.

\section{Experimental Procedure}

Silicon carbide, silicon, and carbon powders were used as starting materials. $\mathrm{SiC}$ powders with two different sizes, that is, micrometric $\mathrm{SiC}(\mu$-SiC, $\sim 15 \mu \mathrm{m}$, Zamin Tavana Co., Mashhad, Iran) and nanometric $\mathrm{SiC}(\mathrm{n}-\mathrm{SiC}, \sim 50 \mathrm{~nm}$, Alfa Aesar, Mass, USA) powders were employed. Powder batches with various weight ratios of $\mathrm{Si} / \mathrm{C}$ in the range of $1-4$ and $(\mathrm{Si}$ $+\mathrm{C}) / \mathrm{SiC}$ between 0.8 and 19 were prepared. These powders were mixed by employing ball milling in methanol media for $1 \mathrm{~h}$. Stainless steel balls with diameter of $4.8 \mathrm{~mm}$ and ball to powder weight ratio of $1: 1$ were utilized. After drying, a small amount of polyvinyl acetate (PVA) binder was added to powder. The powders were sieved to remove agglomerates and large particles. Then the powders were compacted in a steel die, $10 \mathrm{~mm}$ in diameter, at pressure of $125 \mathrm{MPa}$. The green compacts were heated at temperatures of 1400, 1500, and $1600^{\circ} \mathrm{C}$. The heating duration was chosen to be 2 and $4 \mathrm{~h}$. The process was performed under Ar atmosphere to protect the specimens from oxidation.

Density was measured by the Archimedes method according to the ASTM Standard B962 after sealing the surface pores with a water-resistant spray. Specimens for metallographic observations were prepared by the common procedure of grinding on emery papers and fine diamond polishing. The polished sections were studied by an optical microscope. X-ray diffraction (XRD) analysis by using $\mathrm{Cu}$ $\mathrm{K}_{\alpha}$ radiation (wavelength of $1.5406 \AA$ ) working at $40 \mathrm{kV}$ and $30 \mathrm{~mA}$ was utilized for determination of the phases in the specimens. The step size was $0.05^{\circ} \mathrm{s}^{-1}$.

\section{Results}

3.1. Effect of Reaction Sintering Temperature. Figure 1 shows the effect of reaction sintering temperature on the density of SiC-Si-C ceramics with different $\mathrm{SiC}$ particle sizes and

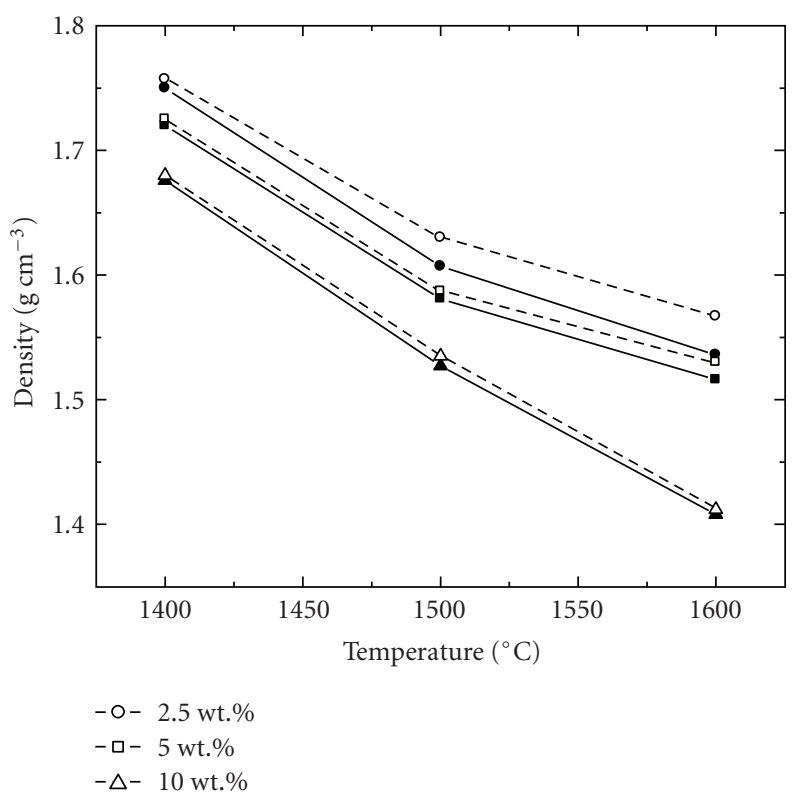

Figure 1: Density of SiC-Si-C ceramics as a function of RS temperature at different amounts of $\mathrm{Si}(2.5,5$ and $10 \mathrm{wt} . \%)$ by using $\mu$-SiC (hollow symbols) and $\mathrm{n}$-SiC (solid symbols) powders. RS time was $2 \mathrm{~h}$, and $\mathrm{Si} / \mathrm{C}$ ratio was 1 .

Si powder contents. Si/C ratio of 1 and RS duration of $2 \mathrm{~h}$ were used. The density of specimens was decreased by increasing the RS temperature from 1400 to $1600^{\circ} \mathrm{C}$, especially at higher amounts of Si powder. The microstructure of ceramic specimens at different RS temperatures is depicted in Figure 2. In general, the microstructure consists of SiC (light gray regions), $\mathrm{C}$ (dark gray regions), and $\mathrm{Si}$ (white regions) phases. Therefore, unreacted Si and $\mathrm{C}$ are present in the specimen, especially at $1400^{\circ} \mathrm{C}$ (Figure 2(a)). Additionally, high amounts of porosity can be observed (dark areas) in the microstructure. The amount of unreacted phases was decreased by an increase in the RS temperature (Figures 2(b) and 2(c)). Nevertheless, the porosity was significantly increased at the higher RS temperatures. Consequently, the specimens reaction-bonded at 1500 and $1600^{\circ} \mathrm{C}$ are very brittle and weak. XRD patterns of ceramic materials produced from $\mathrm{n}-\mathrm{SiC}$ particles by RS at 1400 and $1600^{\circ} \mathrm{C}$ for $2 \mathrm{~h}$ are illustrated in Figure 3 . As it can be seen, only $\beta$-SiC peaks appear in the diffraction patterns. The diffraction peaks were slightly intensified by increasing the RS temperature. Therefore, amplification of diffraction peaks is mainly attributed to the formation of new $\beta$-SiC phase via the RS of Si and C powders.

3.2. Effect of Reaction Sintering Time. The influence of RS duration on the density of SiC-Si-C ceramics is shown in Figure 4 . The density of ceramics was increased by increasing the RS time. The rate of increasing in the density is higher for specimens prepared from $\mathrm{n}-\mathrm{SiC}$ compared to that of $\mu$-SiC. Again, the density was reduced by increasing the Si content. Figure 5 illustrates the microstructure of ceramic specimens processed for 2 and $4 \mathrm{~h}$ at $1400^{\circ} \mathrm{C}$. It is clear that the amount of porosity was reduced at longer times of RS. It is important 


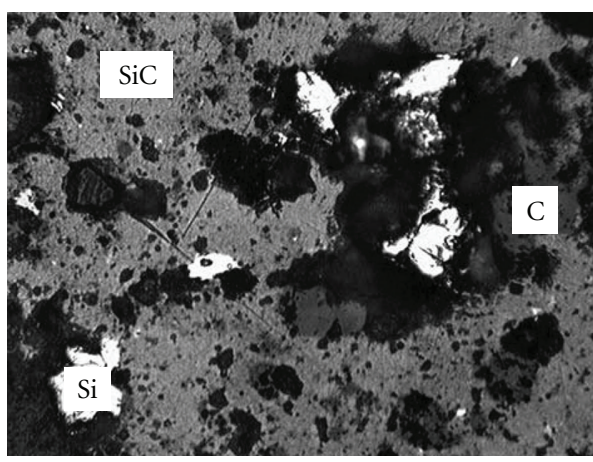

(a)

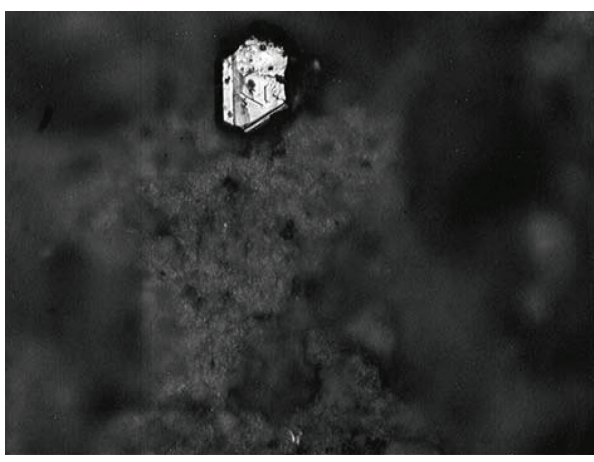

(b)

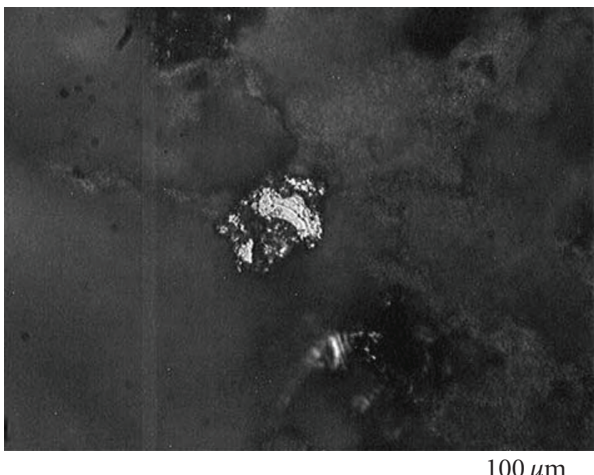

$100 \mu \mathrm{m}$

(c)

Figure 2: Optical micrographs from SiC-Si-C ceramics at RS temperatures of (a) 1400 , (b) 1500 , and (c) $1600^{\circ}$ C. Si powder content of $10 \mathrm{wt} . \%, \mathrm{Si} / \mathrm{C}$ ratio of 1 , initial $\mathrm{SiC}$ particle size of $50 \mathrm{~nm}$, and RS time of $2 \mathrm{~h}$ were used.

to note that unreacted $\mathrm{Si}$ and $\mathrm{C}$ phases were present even after RS for $4 \mathrm{~h}$ (Figure 5(b)). As it can be seen in Figure 3, XRD patterns show $\beta$-SiC reflections only after $4 \mathrm{~h} R \mathrm{RS}$ at $1400^{\circ} \mathrm{C}$.

3.3. Effect of Initial Si and C Content. Figure 6 shows the variation of density as a function of $\mathrm{Si}$ and $\mathrm{C}$ content for $\mathrm{SiC}$ $\mathrm{Si}-\mathrm{C}$ ceramics with $\mathrm{Si} / \mathrm{C}$ ratio of 1 . The density was decreased by increasing the amount of $\mathrm{Si}$ or $\mathrm{C}$ in the compacts. The rate of reduction is steeper for the specimens produced from micrometric SiC powders. This effect was also observed at different RS temperatures (Figure 1) and RS times (Figure 4). As shown in Figure 7, the porosity was increased at higher

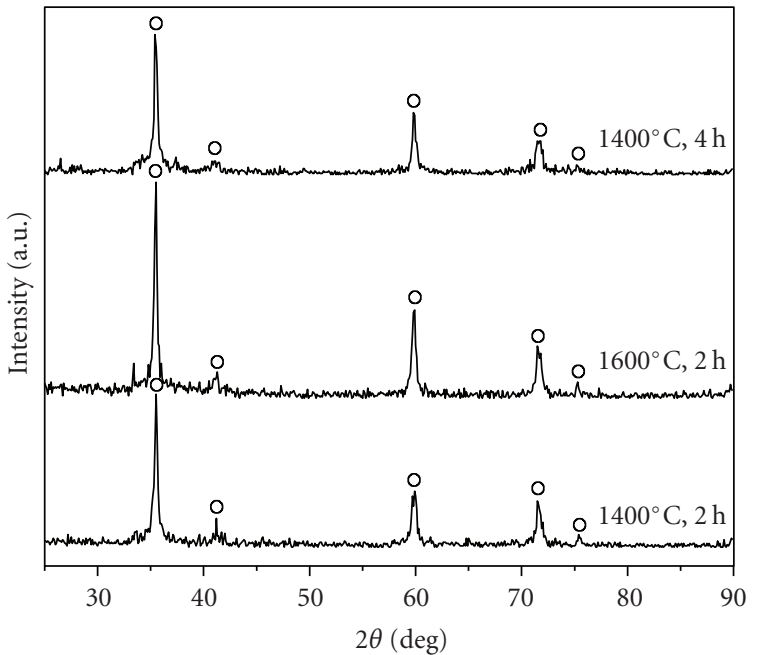

$\circ \beta-\mathrm{SiC}$

FIgure 3: XRD patterns of SiC-Si-C ceramics at different RS temperatures and times. Si powder content of $5 \mathrm{wt} . \%$, Si/C ratio of 1 and initial SiC particle size of $50 \mathrm{~nm}$ were used.

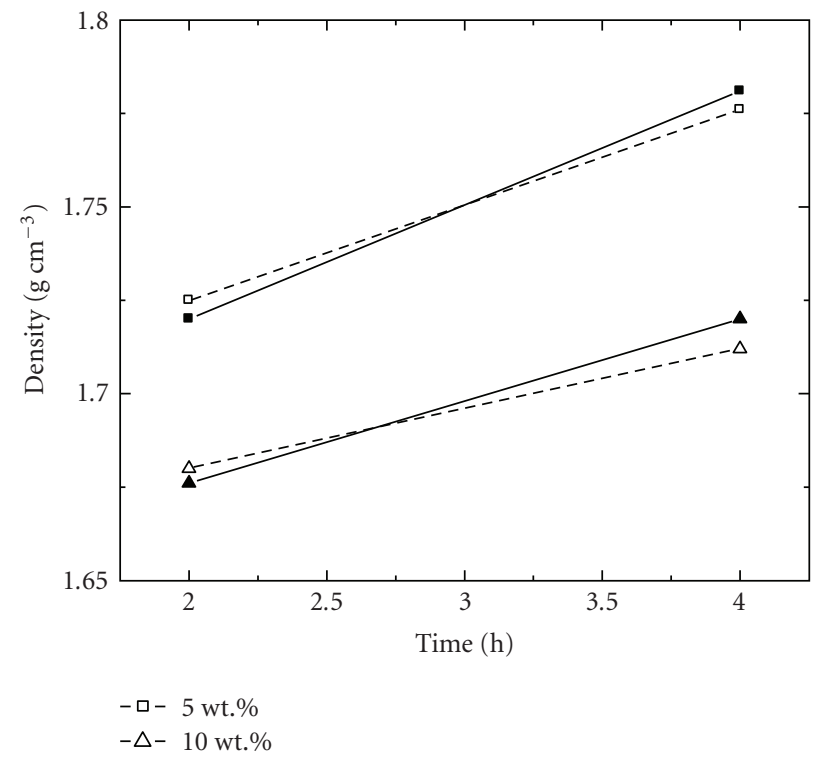

Figure 4: Changes of density of SiC-Si-C ceramics with RS time at different amounts of $\mathrm{Si}$ ( 5 and $10 \mathrm{wt} . \%$ ) by using $\mu$-SiC (hollow symbols) and n-SiC (solid symbols) powders. RS temperature was $1400^{\circ} \mathrm{C}$ and $\mathrm{Si} / \mathrm{C}$ ratio was 1 .

amounts of $\mathrm{Si}$ and $\mathrm{C}$ in the mixed powder. Moreover, the amounts of unreacted Si and C were significantly increased.

3.4. Effect of Si/C Ratio. Changes in the density of ceramic compacts with different $\mathrm{Si} / \mathrm{C}$ ratios are depicted in Figure 8. At a fixed amount of $\mathrm{C}$ in the starting powder mixture, the density was reduced by an increase in the $\mathrm{Si} / \mathrm{C}$ ratio, especially at higher $\mathrm{C}$ content (Figure 8(a)). The microstructure of SiC-Si-C ceramics at initial C content of $5 \mathrm{wt} . \%$ at $\mathrm{Si} / \mathrm{C}$ ratios of 2 and 4 is shown in Figure 9 . The porosity 


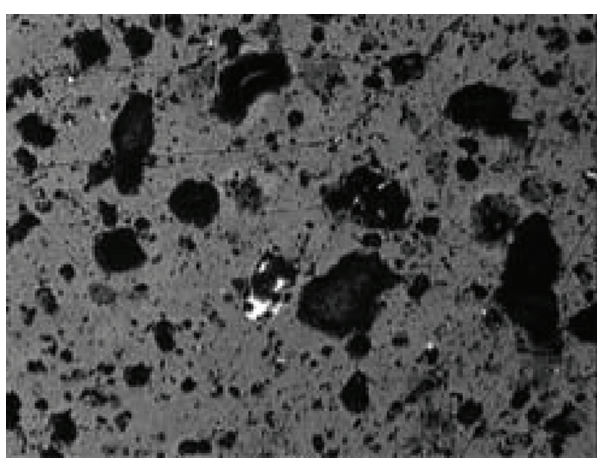

(a)

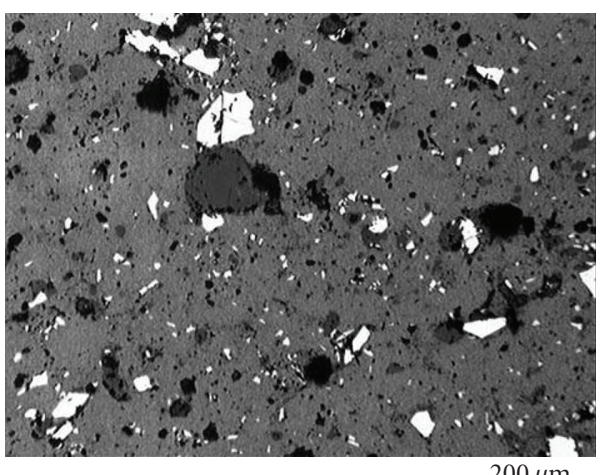

$200 \mu \mathrm{m}$

(b)

Figure 5: Microstructure of SiC-Si-C ceramics by using $\mathrm{n}-\mathrm{SiC}$ powders at RS times of (a) 2 and (b) $4 \mathrm{~h}$. RS temperature of $1400^{\circ} \mathrm{C}$, $\mathrm{Si} / \mathrm{C}$ ratio of 1 , and Si amount of $5 \mathrm{wt} . \%$ were employed.

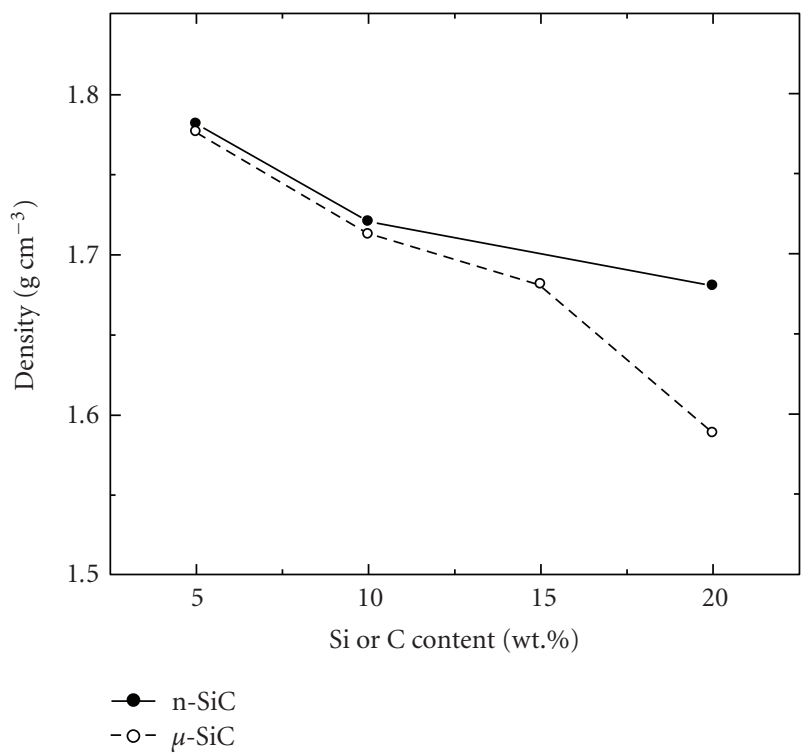

Figure 6: Effect of Si or C content on the density of SiC-Si-C specimens with $\mathrm{Si} / \mathrm{C}$ ratio of 1 . Ceramic compacts reaction-bonded at $1400^{\circ} \mathrm{C}$ for $4 \mathrm{~h}$.

was not considerably changed by increasing the Si content from 5 to 10 wt.\% (Figures $7(\mathrm{a})$ and $9(\mathrm{a})$ ). Nevertheless, a large fraction of porosity and unreacted $\mathrm{Si}$ and $\mathrm{C}$ phases are

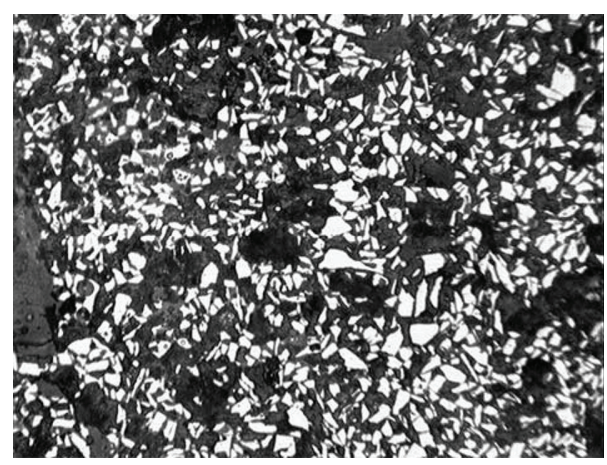

(a)

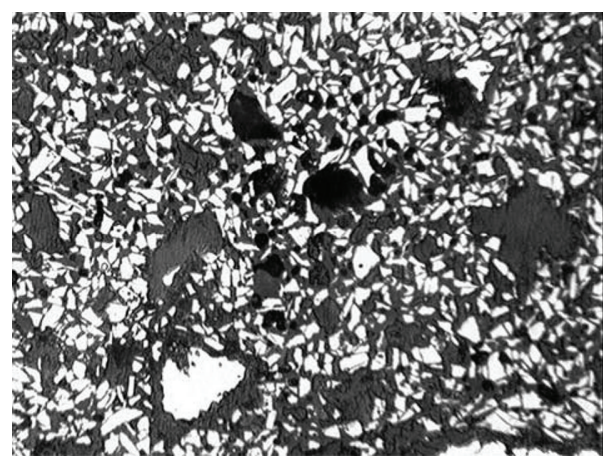

(b)

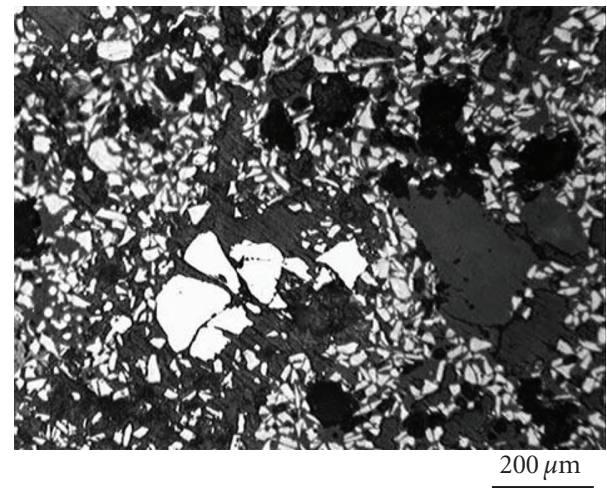

(c)

Figure 7: Microstructure of SiC-Si-C specimens by using $\mu$-SiC powders at Si amount of (a) 5, (b) 10, and (c) $20 \mathrm{wt} . \%$. Compacts with $\mathrm{Si} / \mathrm{C}$ ratio of 1 were reaction-bonded at $1400^{\circ} \mathrm{C}$ for $4 \mathrm{~h}$.

observable at $\mathrm{Si} / \mathrm{C}$ ratio of 4 (Figure 9(b)). The presence of $\mathrm{Si}$ phase around $\mathrm{SiC}$ particles and microcracks within them is also noticed. XRD patterns of ceramic specimens produced from $\mu$-SiC powders at two different $\mathrm{Si} / \mathrm{C}$ ratios are shown in Figure 10. At $\mathrm{Si} / \mathrm{C}=1, \alpha-\mathrm{SiC}$ and $\beta$-SiC phases are detected. The appearance of weak $\mathrm{SiO}_{2}$ reflections can be attributed to the presence of this phase in the initial powder. On the other hand, Si peaks appear in addition to $\alpha$-SiC, $\beta$-SiC, and $\mathrm{SiO}_{2}$ peaks in the diffraction pattern of ceramic with $\mathrm{Si} / \mathrm{C}=4$. This is related to the remaining of unreacted $\mathrm{Si}$ in the specimen as shown in Figure 9(b).

At a fixed amount of $\mathrm{Si}$ in the starting powder, the density of SiC-Si-C specimens was increased by an increase in the 


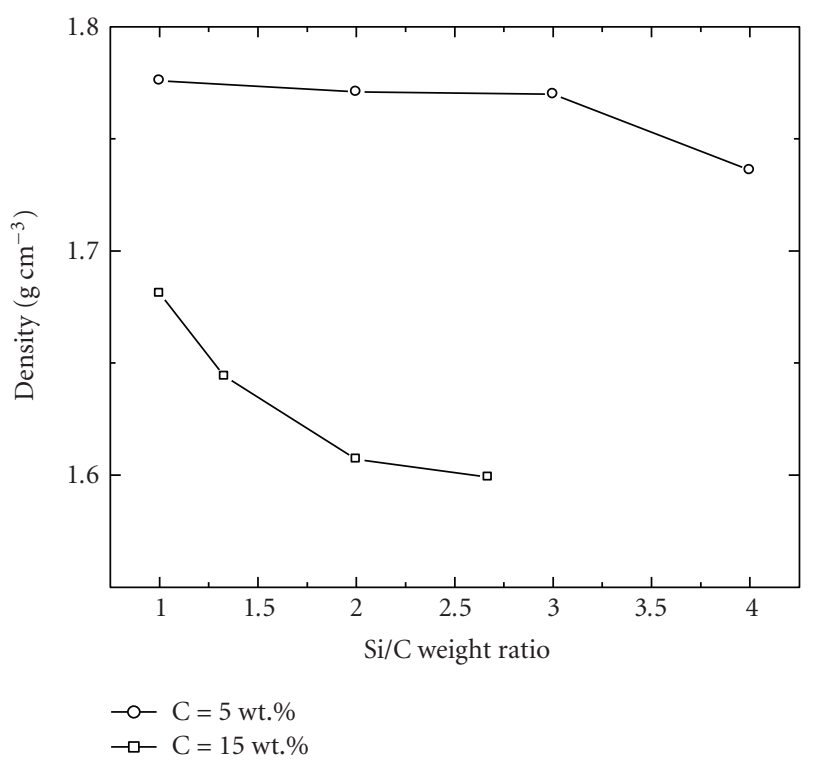

(a)

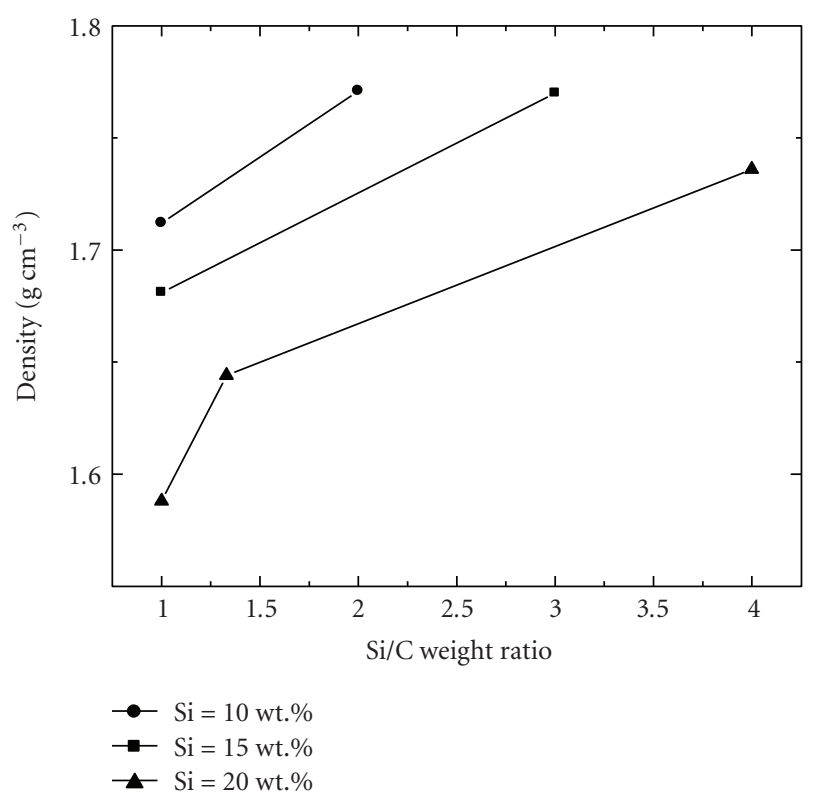

(b)

Figure 8: Density of SiC-Si-C compacts as a function of $\mathrm{Si} / \mathrm{C}$ ratio at fixed amount of initial (a) C powder and (b) Si powder. Specimens were produced by RS at $1400^{\circ} \mathrm{C}$ for $4 \mathrm{~h}$.

Si/C ratio (Figure $8(\mathrm{~b})$ ). In other words, the density was reduced at higher $\mathrm{C}$ contents.

3.5. Effect of SiC Particle Size. The role of initial SiC particle size on the density is related to the RS duration. The use of micrometric $\mathrm{SiC}$ particles resulted in higher density at shorter times of RS, that is, $2 \mathrm{~h}$ (see Figures 1 and 4). Nevertheless, at a longer RS duration, nanometric SiC particles were yielded to the higher densification (Figures 4 and 6). In addition, lower porosity and unreacted phases can be obtained (Figures 5(b) and 7(a)).

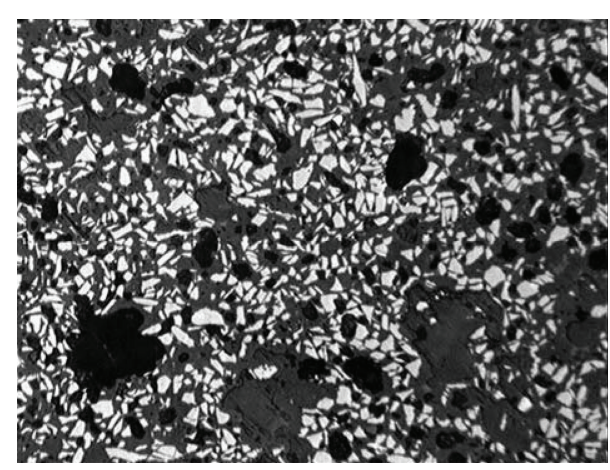

(a)

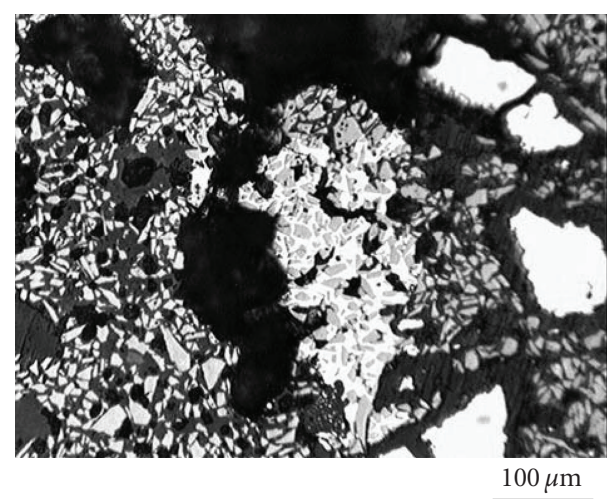

(b)

FIgURE 9: Optical micrographs from the microstructure of SiC-Si$\mathrm{C}$ ceramics by using $\mu$-SiC powders at initial C content of $5 \mathrm{wt} . \%$ and $\mathrm{Si} / \mathrm{C}$ ratio of (a) 2, (b) 4 . Specimens were reaction-bonded at $1400^{\circ} \mathrm{C}$ for $4 \mathrm{~h}$.

\section{Discussion}

It was found that reaction sintering processing condition (temperature and time), chemical composition of the starting powder ( $\mathrm{Si} / \mathrm{C}$ ratio and amount of $\mathrm{Si}$ and $\mathrm{C}$ ), and initial SiC particle size can significantly alter the densification behavior of SiC-Si-C ceramics during RS process. Therefore, the density and microstructure can be influenced.

During RS, the carbon reacts with silicon to form the new $\beta$-SiC phase which grows onto the original $\operatorname{SiC}(\alpha-$ $\mathrm{SiC}$ for micrometric or $\beta$-SiC for nanometric particles) and hence bonds the compact together. While this reaction is a diffusion-controlled process, it is expected that higher temperature and longer time of RS can progress the reaction and improve the densification. Nevertheless, the results showed that the densification was degraded by increasing the RS temperature in the range of $1400-1600^{\circ} \mathrm{C}$ (Figure 1). Indeed, although higher $\beta$-SiC was formed (Figure 3 ), there was no evidence of densification at 1500 and $1600^{\circ} \mathrm{C}$ (Figures 2 (b) and 2(c)). Since the melting point of pure silicon is $\sim 1410^{\circ} \mathrm{C}$ [17], silicon melted during the RS at 1500 and $1600^{\circ} \mathrm{C}$. Some of the silicon reacted with carbon to form $\beta$-SiC. However, most of the silicon phase came out of the compact during RS. As a result, the amount of porosity was grown and compact lost its integrity. Nevertheless, RS was performed in solid state at $1400^{\circ} \mathrm{C}$, and better densification 


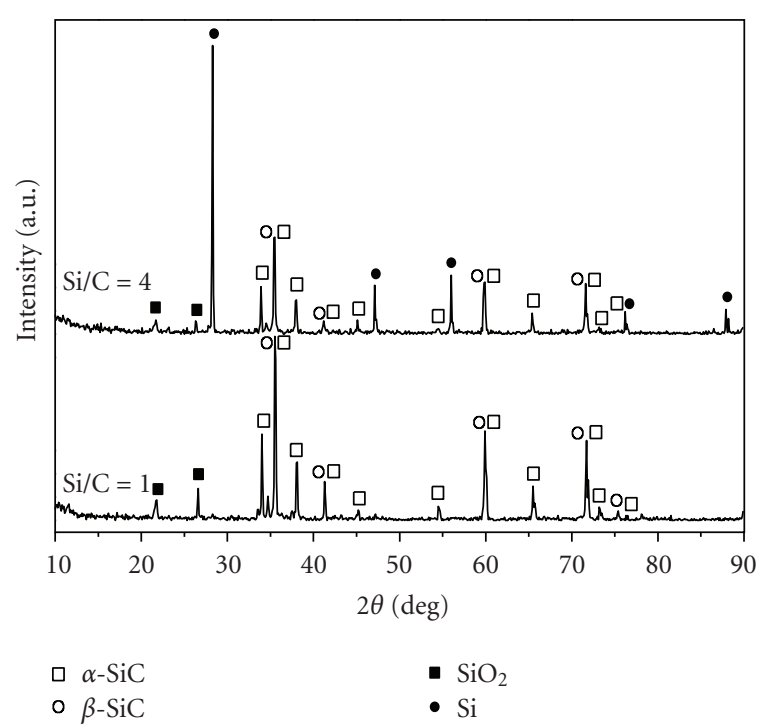

FIgURE 10: XRD patterns of SiC-Si-C ceramics at Si/C ratio 1 and 4 by using $\mu$-SiC powders. C powder content of $5 \mathrm{wt} . \%$, RS temperature of $1400^{\circ} \mathrm{C}$, and RS time of $4 \mathrm{~h}$ were used.

was achieved by applying prolonged RS (Figure 4). While there were some unreacted carbon and silicon phases within the compacts, it can be concluded that using longer RS times can lead to enhanced reaction and superior densification.

The results showed that increasing the amount of $\mathrm{Si}$ and/or $\mathrm{C}$ powders in the starting powder mixture at stoichiometric $(\mathrm{Si} / \mathrm{C}=1)$ or nonstoichiometric $(\mathrm{Si} / \mathrm{C} \neq 1)$ ratio has a detrimental influence on the densification of ceramic material (Figures 1, 4, 6 and 8). As SiC-Si-C ceramics consisted of $\alpha$-SiC or $\beta$-SiC (density of $3.21 \mathrm{~g} \mathrm{~cm}^{-3}$ ), residual $\mathrm{Si}$ (density of $2.33 \mathrm{~g} \mathrm{~cm}^{-3}$ ), and residual C (density of $2.67 \mathrm{~g} \mathrm{~cm}^{-3}$ ) in the ceramic body, the density was proportional to the amount of unreacted Si and C phases [6]. The amount of free silicon and carbon phases was significantly increased by an increase in the amount of Si and/or $\mathrm{C}$ in the starting powder mixture (Figures 7 and 9). Therefore, the density of ceramic compacts was reduced at higher contents of Si and/or C. On the other hand, since the interfaces between $\mathrm{SiC}$ and $\mathrm{Si}$ as well as the brittle free silicon phase are preferential paths for fracture, the presence of free silicon is detrimental for production of $\mathrm{SiC}$ ceramics [18]. Additionally, the strength and creep resistance deteriorate at temperatures above $1400^{\circ} \mathrm{C}$ due to existing free silicon [11]. Microcracks were found within some of the free silicon phase at high amount of Si in the starting material (see Figure 9(b)). These microcracks can be generated due to the crystallographic mismatch and differences in thermal expansion coefficient of $\mathrm{SiC}$ and silicon phases [11]. It is pertinent to point out that one of the ways to reduce the free silicon content in the reaction-bonded $\mathrm{SiC}$ ceramics produced via infiltration of $\mathrm{Si}$ into $\mathrm{SiC} / \mathrm{C}$ preforms is increasing the carbon content in the preform. Wilhelm et al. [12] reported that the free silicon content reduced from 26 to 12 vol.\% by increasing the phenol formaldehyde resin from 15 to $25 \mathrm{wt} . \%$ in the SiC/C preform. Nevertheless, the results of this study showed that increasing the carbon content in the initial powder mixture reduced the density of sintered compacts (Figure $8(\mathrm{~b})$ ). This is mainly attributed to the difference in the mechanism of RS process in this study (solid-state reaction) with conventional infiltration of silicon into a carbon-contained preform (liquid-phase reaction).

The results demonstrated that using nanometric SiC particles instead of micrometric ones in the starting powder mixture improved densification at longer RS duration and higher amount of Si or C (Figures 4 and 6). It is well known that reduction of the initial powder particle size leads to an increase in the surface area of the powder. Therefore, it is estimated that higher amount of newly formed $\mathrm{SiC}$ phase is required for bonding the nanometric $\mathrm{SiC}$ powders compared to micrometric ones. Consequently, RS for longer time and higher amount of Si and C can result in higher density and lower amount of unreacted phases.

\section{Conclusions}

The density and microstructure of porous $\mathrm{SiC}-\mathrm{Si}$-C ceramics produced by reaction sintering were investigated. The most important findings can be summarized as follows.

(1) Increasing the reaction sintering temperature higher than $1400^{\circ} \mathrm{C}$ degraded the densification, and specimens had low strength due to numerous and large porosities remaining within them.

(2) Increasing the RS time from 2 to $4 \mathrm{~h}$ improved densification and less unreacted silicon and carbon phases were remained.

(3) Using the higher amount of silicon and/or carbon powders in the initial powder mixture had a detrimental influence on the densification. Additionally, higher amount of free silicon and carbon phases remained in the specimens.

(4) Superior densification was achieved by using nanometric SiC particles in the initial ceramic powder mixture compared to micrometric powders especially at longer RS durations and higher amount of Si and $\mathrm{C}$ in the starting powder mixture.

\section{References}

[1] S. Suyama, T. Kameda, and Y. Itoh, "Development of highstrength reaction-sintered silicon carbide," Diamond and Related Materials, vol. 12, no. 3-7, pp. 1201-1204, 2003.

[2] H. Basu, M. M. Godkhindi, and P. G. Mukunda, "Investigation on the reaction sintering of porous silicon carbide," Journal of Materials Science Letters, vol. 18, no. 5, pp. 389-392, 1999.

[3] Y. Wang, S. Tan, and D. Jiang, "The effect of porous carbon preform and the infiltration process on the properties of reaction-formed SiC," Carbon, vol. 42, no. 8-9, pp. 1833-1839, 2004.

[4] A. Gubernat, L. Stobierski, and P. Łabaj, "Microstructure and mechanical properties of silicon carbide pressureless sintered with oxide additives," Journal of the European Ceramic Society, vol. 27, no. 2-3, pp. 781-789, 2007. 
[5] T. Yano, K. Budiyanto, K. Yoshida, and T. Iseki, "Fabrication of silicon carbide fiber-reinforced silicon carbide composite by hot-pressing," Fusion Engineering and Design, vol. 41, no. 1-4, pp. 157-163, 1998.

[6] U. Paik, H. C. Park, S. C. Choi, C. G. Ha, J. W. Kim, and Y. G. Jung, "Effect of particle dispersion on microstructure and strength of reaction-bonded silicon carbide," Materials Science and Engineering A, vol. 334, no. 1-2, pp. 267-274, 2002.

[7] R. Fielding, M. Meyer, J. F. Jue, and J. Gan, "Gas-cooled fast reactor fuel fabrication," Journal of Nuclear Materials, vol. 371, no. 1-3, pp. 243-249, 2007.

[8] X. P. Liu, L. Wan, Y. Wang, and J. L. Chen, "Manufacture of $\mathrm{SiC} / \mathrm{FeSix}$ composite by reactive infiltration," Material Science and Technology, vol. 13, no. 3, pp. 316-319, 2005.

[9] O. P. Chakrabarti, P. K. Das, and J. Mukerji, "Growth of SiC particles in reaction sintered SiC," Materials Chemistry and Physics, vol. 67, no. 1-3, pp. 199-202, 2001.

[10] C. B. Lim and T. Iseki, "Strength variations of reactionsintered $\mathrm{SiC}$ heterogeneously containing fine-grained $\beta$-SiC," Journal of Materials Science, vol. 23, no. 9, pp. 3248-3253, 1988.

[11] M. Wilhelm and W. Wruss, "Influence of annealing on the mechanical properties of SiC-Si composites with sub-micron $\mathrm{SiC}$ microstructures," Journal of the European Ceramic Society, vol. 20, no. 8, pp. 1205-1213, 2000.

[12] M. Wilhelm, S. Werdenich, and W. Wruss, "Influence of resin content and compaction pressure on the mechanical properties of SiC-Si composites with sub-micron $\mathrm{SiC}$ microstructures," Journal of the European Ceramic Society, vol. 21, no. 7, pp. 981-990, 2001.

[13] O. P. Chakrabarti, S. Ghosh, and J. Mukerji, "Influence of grain size, free silicon content and temperature on the strength and toughness of reaction-bonded silicon carbide," Ceramics International, vol. 20, no. 5, pp. 283-286, 1994.

[14] S. Suyama, Y. Itoh, A. Kohyama, and Y. Katoh, "Development of high strength reaction-sintered silicon carbide," Journal of the Ceramic Society of Japan, vol. 109, no. 1268, pp. 315-321, 2001.

[15] O. P. Chakrabarti and P. K. Das, "High temperature loaddeflection behaviour of reaction bonded SiC (RBSC)," Ceramics International, vol. 27, no. 5, pp. 559-563, 2001.

[16] M. Blecha, W. Schmid, A. Krauth, and W. Wruss, "Herstellung grobkörniger, auf hohen SiC-Gehalt optimierter SiC-CGrünkörper für die Herstellung von SiSiC," Sprechsaal, vol. 123, pp. 263-268, 1990.

[17] R. Hull, Properties of Crystalline Silicon, The Institution of Electrical Engineers, London, UK, 1999.

[18] J. N. Ness and T. F. Page, "Microstructural evolution in reaction-bonded silicon carbide," Journal of Materials Science, vol. 21, no. 4, pp. 1377-1397, 1986. 

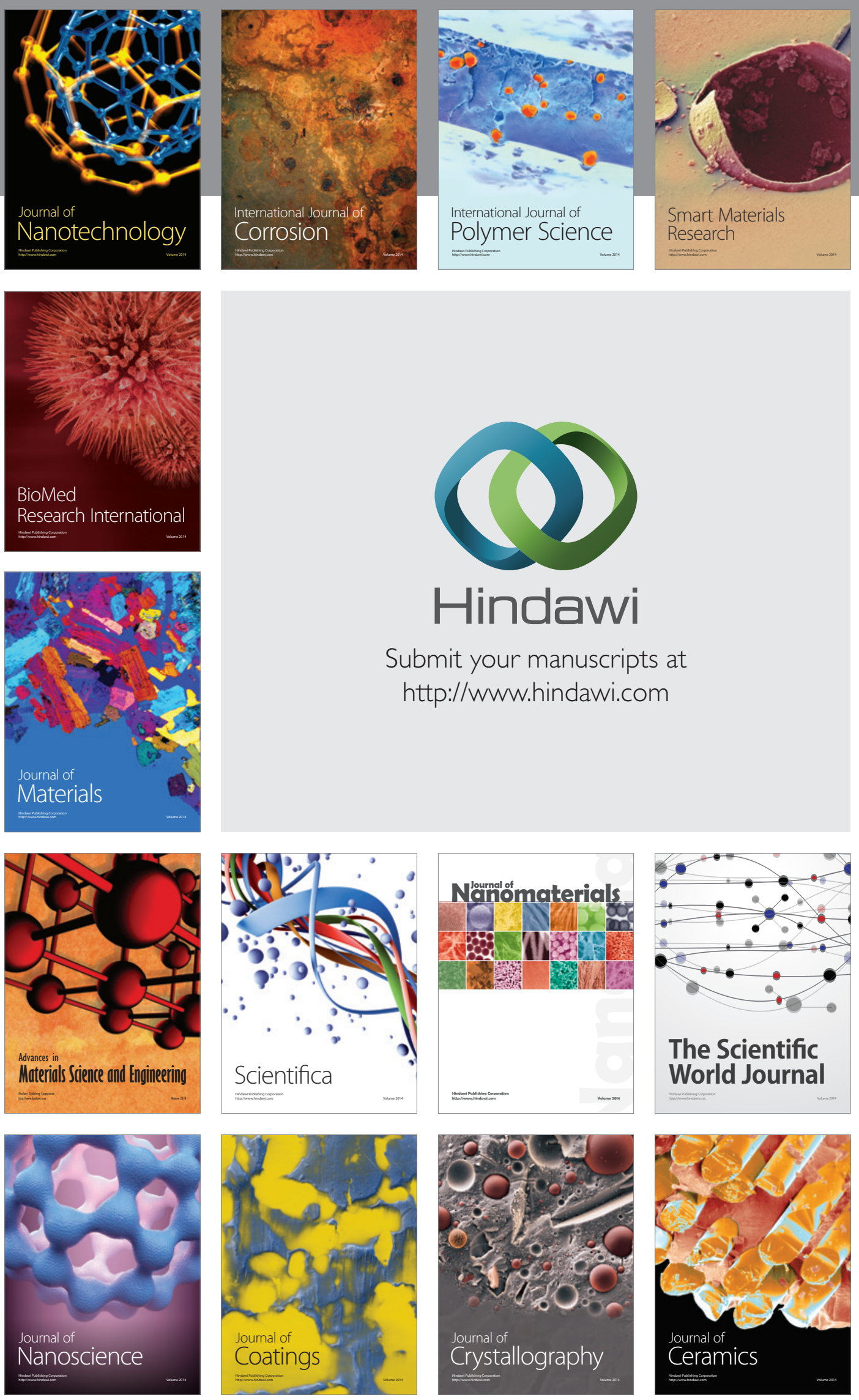

The Scientific World Journal

Submit your manuscripts at

http://www.hindawi.com

\section{World Journal}

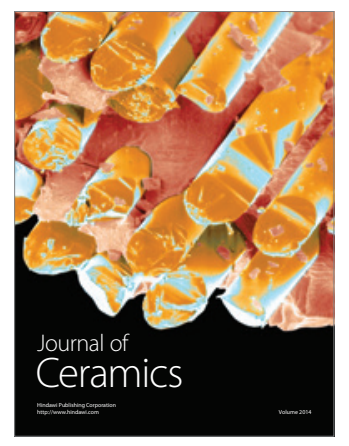

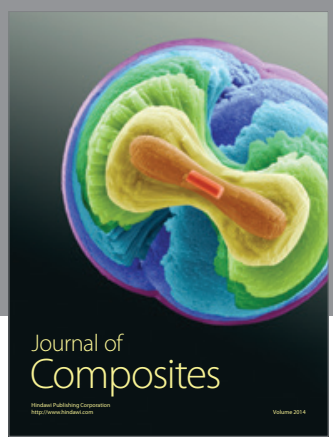
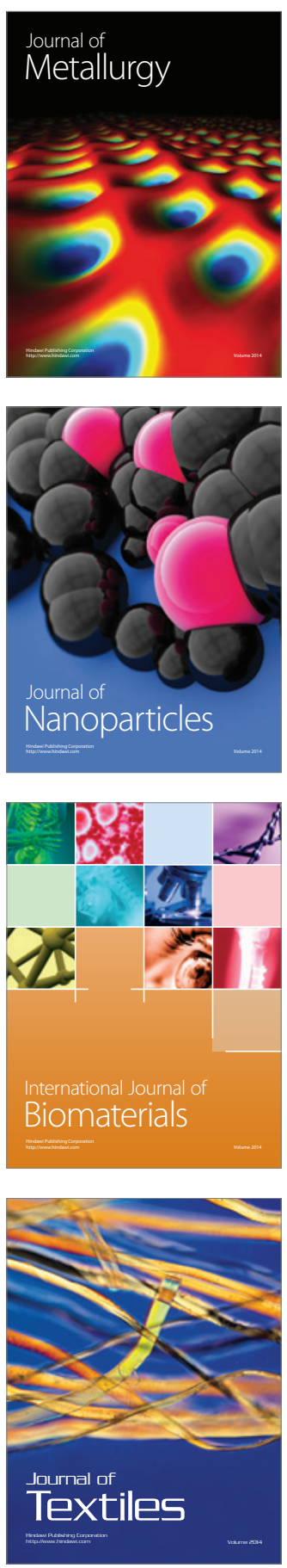